Copyright (C) 2016 by Academic Publishing House Researcher

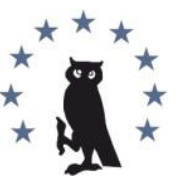

Published in the Russian Federation

European Researcher

Has been issued since 2010.

ISSN 2219-8229

E-ISSN 2224-0136

Vol. 110, Is. 9, pp. 500-507, 2016

DOI: 10.13187/er.2016.110.500

www.erjournal.ru

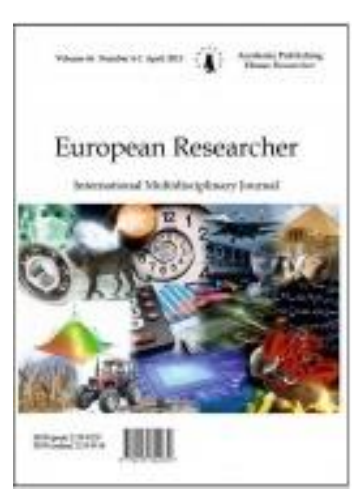

UDC 159.9

\title{
'Unattractive, So Hopeless?' Feelings of Physical Unattractiveness and Hopelessness among Senior High Students
}

\author{
Gloria Baaba Aggrey a, * \\ Nkansah Anakwah a, b, c \\ Jacob Owusu Sarfo c, d, e
}

a University of Ghana, Ghana

b Methodist University College, Ghana

c KAD International, Ghana

d University of Cape Coast, Ghana

e All Nations University College, Ghana

* Corresponding author

E-mail addresses: babsygrey@gmail.com (G. B. Aggrey *), anaben.afrique@hotmail.com

(N. Anakwah), sarfojo@yahoo.com (J. O. Sarfo)

\section{Abstract}

This study sought to investigate the influence of feelings of unattractiveness on hopelessness among adolescents. Using the cross-sectional survey design, total of 150 participants from two categories of senior high schools were sampled for the study. To achieve the aim for this study, the interaction effect of the following on hopelessness was investigated: gender and perceived attractiveness, school and perceived attractiveness and, religiosity and perceived attractiveness. Results showed that there was a significant positive relationship between perceived physical attractiveness and hopefulness. Implications of findings are discussed.

Keywords: attractiveness, unattractiveness, hopelessness, hopefulness, gender, religiosity, senior high school, student.

\section{Introduction}

Over decades, physical appearance had been noted as a vital contributing factor affecting the self-esteem of adolescents (Pardin, Lerner, \& Spiro, 1981). According to Bersheid and Walster (1972), physical characteristics in those days seem to stimulate differential expectations of others depending on the degree of perceived attractiveness. The implication of receiving relatively consistent feedback from others based on physical appearance makes physically attractive and unattractive individuals more likely to develop self- images, social temperaments and styles of interpersonal behaviour that differ (Tucker, 1983).

Emphasis on being physically attractive begins in infancy (Langlois et al., 1987), continues throughout childhood, adolescence (Brooks-Gunn, \& Petersen, 1983; Lerner, \& Foch, 1987) and college years (Bryne, Ervin, \& Lambert, 1970). Cash and Jandra (1984) stated that both children and adolescents differ in their response to people depending on the appearance and attractiveness 
of those people. Early as the pre-school and elementary school years, children who are better looking typically receive higher status from their peers (Kleck, Richardson, \& Roland, 1974; Vaghn, \& Langlois, 1983). Bersheid, Walster and Borhstedt (1973) observed that adolescents who considered themselves as unattractive were the most unhappy group of respondents in a national study of personal happiness. Other researches show that, concern about physical appearance is the most worrisome problem among high school students (Eme, Maisak, \& Goodale, 1979). Attractiveness has been found not only related to social status in childhood and adolescence (Henggeler, \& Borduin, 1990) but also to indices of happiness, popularity, sociability and success in adulthood (Bersheid, \& Walster, 1972). As the millennium drew closer, Lewis and Rosenblum (1999) have indicated that perceptions of physical attractiveness among boys and girls are not significantly different until age fifteen. Talbot (2012) however found no difference between men and women's ratings of self-perception of attractiveness.

As adolescents pay increasing attention to their body features and what they perceive important others think of them, they begin to form an ideal physical self-concept and definite stereotypes of typical and/or ideal physical appearance (Rauste-von Wright, 1989). Adolescents' views on appearance are strongly influenced by socially defined stereotypes and self-concept. This is likely to be adversely affected when one's features are perceived as deviation from what is normal (Page, 1992). Skin colour, appearance and social class have also been cited to be strongly linked (Masi de Casanova, 2004). Masi de Casanova (2004) for example have suggested that people of low social class have lower self-esteem that those of average and higher social class status. Other studies have also suggested physical attractiveness has an influence on hopelessness (Page, 1992). Bersheid and Walster (1972) indicated that such studies suggest that physically attractive people are hopeful and this hopefulness may be linked to confidence that one's physical attractiveness can turn things in his/her favour. In a systematic review, Anakwah, Wiafe-Akenteng, Sarfo and Parimah (2015) found evidence to suggest that physical attractiveness can even bias decision making in the court room.

Also, Abrams, Allen and Gray (1993) acknowledge that cultural variables play a vital role in body satisfaction. Those who accept European or Western standards view others whose physical appearance most closely resemble European ideals as more desirable (Chambers, Clark, Dantzler, \& Barldwin, 1994). It must be well noted that not all cultures place the same beauty value on body features. Body attitude measures have been consistently associated with body mass in a direction that suggest that heaviness or high weight levels produce body dissatisfaction and unfavourable fitness and appearance evaluations (Harris, Walters, \& Waschull, 2001). However, a wider range of body weight receives acceptance in African-American culture compared to Caucasian culture (Freedman, Carter, Sbrocco, \& Gray, 2004). Most adolescents who perceive themselves as 'fat', 'obese', or 'large' usually have unhealthy eating habits. Wilson, Sargent and Dias (1994) found out that African American adolescents who perceive themselves as too large tend to skip meals to control their weight. Most become anorexics or bulimics as a result. Perry (1992) suggested that today's specifications for blonde and thin in the European and American societies is not an easy task since most girls get bigger during adolescence.

However, religious involvement cushions the harmful effects of certain types of adversity on black self-esteem (Homan, \& Boyatzis, 2009). 'This stress-buffering pattern is particularly evident with regard to states of the physical body, its attractiveness and its health. Frequent participation in church communities appears to moderate the negative consequences of physical unattractiveness for black self-esteem' (Ellison, 1993). Pardin, et al. (1981) buttressed the initiating viewpoint by commenting that, physical attractiveness when rated is consistently seen to be positively related to self-esteem. The association between physical appearance (real or perceived) and self-esteem led to the hypothesis that perceptions to physical attractiveness may be related to other important aspects of adolescent mental health (Page, 1992).

Perceptions of unattractiveness are normally followed with hopelessness. Hopelessness has been implicated in conditions such as alcoholism, physical illness, sociopathy, and schizophrenia (Beck, Weissman, Lester, \& Trexler, 1974). It has also been shown to be a key psychological factor in suicidal behaviours of adults (Beck, 1986). Scores on the Beck Hopelessness Scale have been found to be a significant predictor of the severity of suicidal intent and the extent of suicidal ideation among those hospitalized for attempted suicide (Beck, Kovacs, \& Weissman, 1975). 
Beck's theory of depression [Negative or Cognitive Triad] is of the view that, thoughts about the self, the external world, and the future all contribute to our mental health (Beck, 1995). Beck theorized that all three of these beliefs become negative a result of common thought distortions and this leads to depression. From Beck's theory it can be deduced that for someone to feel hopeless, it depends on his or her cognitive interpretation of an event or situation such as physical attractiveness.

Another model that supports this theory is the ABCDE model by Albert Ellis (Ellis, 2008). Ellis's ABCDE model was formerly known as the ABC model. In the ABCDE model, A, B, and C represent the three-step model which explains how events lead to thoughts, which in turn lead to beliefs and then feelings [A - Activating event, B - Belief, and C - emotional Consequence]. Ellis's model simply replaces these three terms with more easily remembered terms. According to Ellis, irrational beliefs are toxic because they function as rigid, dogmatic demands that we apply to ourselves. For example, "I must get an A in every class," "I need to be dating someone," or "I must be physically attractive." Although these may be strong preferences, they are not, in fact, "musts" or absolute rules (Ellis, 2008). Moreover, when we tend to couple these demands with overestimations of the consequences of failure like, "If I don't get an A, I'll dropout of school and end up on the street," "If I'm not dating anyone, I'm completely worthless," or "If I am not physically attractive, I will not get anyone to marry me", we develop a negative feeling such as being hopeless. Ellis sees flawed logic in all these self-statements and opportunity for therapeutic benefit in correcting them. To accomplish this correction, Ellis's model adds two more steps, D and E. In his model, D stands for Dispute [this is where you oppose your initial irrational belief], and E stands for Effective new belief.

Page (1992) has therefore suggested that hopelessness represents an aspect of emotional health and well-being and educational professionals should be concerned about it. Kashani, Reid and Rosernberg (1989) stated that little attention has been paid to hopelessness in educational literature and further little research has been conducted among adolescents. According to Beck, et al. (1974), hopelessness has been implicated in conditions such as alcoholism, physical illness, sociopathy, and schizophrenia. Beck (1986) further indicated that hopelessness has also been shown to be a key psychological factor in suicidal behaviour of adults. Regardless of all the negative repercussions of hopelessness, Kashani, et al. (1989) stated that little attention has been paid to hopelessness in educational literature and further little research has been conducted among adolescents. Hence, this study sought to investigate the effect of the perceived attractiveness or unattractiveness of adolescents on their level of hopelessness or hopefulness. The role of gender, class of school and religiosity were also considered in this paper.

\section{Methodology \\ Population}

The population under study was adolescents in Greater Accra Region. The sample frame consisted of Senior High School (S.H.S) students. The sample of S.H.S. students that participated in the study were from a well-endowed school and two less-endowed schools. A sample size of 150 students [72 from a well-endowed school and 78 from two less-endowed schools] participated in the study since a greater power was needed for any difference to be detected. Cohen (1992) indicated that the number of participants in any sample is directly related to the standard deviation of the sampling distribution and the more the participants, the narrower the distribution and greater the likelihood that any differences will be discovered (i.e., the greater the power). Ages from 13 to 16 had a total frequency of 76 (50.7\%) and ages from 17 to 21 had a frequency of 72 (48\%). Students from a well-endowed school had a frequency of $72(48 \%)$ and from two less-endowed schools had a frequency of 78 (52\%). Males were 91 (60.7\%) and females were 59 (39.3\%).

\section{Sampling}

Purposive sampling was used because the target population that was of interest to the researcher was only adolescents in senior high schools.

\section{Measures}

The survey tools that were used were the Beck Hopelessness Scale, the Estimating Physical Attractiveness Scale and the Santa Clara Strength of Religious Faith Questionnaire.

The Beck Hopelessness Scale developed by Aaron Beck is an internationally accepted measure in the prediction of suicide (Forintos, \& Sallai, 2010). BHS is a 20-item true or false scale 
with a coefficient alpha of 0.93 (Beck et al., 1974). Some of the items on the scale include: 'In the future, I expect to succeed in what concerns me most' and 'My future seems dark to me'.

The Santa Clara Strength of Religious Faith Questionnaire (SCSORFQ) by Plante and Boccaccini (1997) was designed to measure the strength of religious faith regardless of denomination and it was found to have a coefficient alpha of .95 and a split-half reliability of .92. Some of the items on the scale include: 'My religious faith is extremely important to me.' and 'I pray daily'.

On the other hand, the Estimating Physical Attractiveness Scale (EPAS) is a fairly new instrument that was developed by Swami, Furnham, Georgiades and Pang (2007). Because of this, little reliability and validity information exist. However, it has been used in a number of studies since its development and has proven to be a good measure of physical attractiveness (Swami et al., 2007). Some of the items on the scale include: 'Overall physical attractiveness' and 'Overall facial attractiveness'.

\section{Procedure}

A letter of consent from the Department of Psychology, University of Ghana requesting for permission to conduct a survey in schools together with a paper containing a brief description of the study and sample of the questionnaire that was administered was sent to the headmistress and some teachers for approval or consent.

When consent was given, the participants were sampled from some of the classes and a brief description of the study was given to them. However, they were partially deceived. They were told that they are being examined on their perceived physical attractiveness; but hopelessness was not mentioned so as to avoid incidents such as the provision of false answers for the fear of tarnishing their images especially before a stranger (researcher). However, after the study, participants were debriefed. To encourage honest responses, participants were assured and reassured of confidentiality and told not to write their names on the questionnaires.

A questionnaire consisting of three sections was administered to each participant. The first section contained demographics such as age and gender. The second section consisted of items from the Beck Hopelessness Scale and items from the Estimating Physical Attractiveness Scale. The final section consisted of items from Santa Clara Strength of Religious Faith Questionnaire. After participants were done answering the questions on the questionnaires, the questionnaires were collected for analysis.

\section{Scoring}

The Beck Hopelessness Scale (BHS) is a 20-item true or false scale. The total score can range from o to 20. Every "true" response attracts a score of 1 and every false response attracts a score of o. Total scores ranging from: o to 3 are considered within the normal range, scores from 4 to 8 identify mild hopelessness, scores from 9 to 14 identify moderate hopelessness, and scores greater than 14 identify severe hopelessness (Beck and Steer, 1988).

However for this study, the Beck Hopelessness Scale was adapted to a 4-point Likert scale ranging from 1 (strongly disagree) to 4 (strongly agree). The BHS contains 9 optimistic and 11 pessimistic questions; but to be able to have higher scores representing scores on hopefulness, the scoring for the pessimistic questions were reversed i.e., $4 \rightarrow 1,3 \rightarrow 2,2 \rightarrow 3$ and $1 \rightarrow 4$. As a result a total score of 80 represented the highest score on hopefulness and 20 represented the lowest score on hopefulness (severe hopelessness). In short, increasing scores from 20 pointed towards an increasing order of magnitude for level of hopefulness.

Also, the Estimating Physical Attractiveness is a 20-item scale. Each score on this instrument is compared to the normal distribution which has a Mean (M) of 100 and a Standard Deviation (SD) of 15 . Based on this guide a rating of 55 is considered very unattractive, 70 unattractive, 85 low average, 100 average, 115 high average, 130 attractive, and 145 as very attractive (Swami et al., 2007).

For this study, one's total score on perceived attractiveness was scored by finding the mean of the scores for each item and mean scores below 100 were considered as unattractive and mean scores from 100 and above were considered as attractive.

The Santa Clara Strength of Religious Faith Questionnaire is a 10-item scale that is measured on a 4-point Likert scale ranging from strongly disagree (1) to strongly agree (4). Therefore, a total of 40 represented very high religiosity whiles a total of 10 represented very low religiosity. 


\section{Results}

The result as shown in Table 1 indicated that there was a significant positive relationship between perceived attractiveness and hopefulness $\left[r_{(148)}=.20, \rho=.01\right]$.

Table 1: Relationship between perceived attractiveness and hopefulness

\begin{tabular}{|l|l|l|}
\hline Study variables & $\boldsymbol{r}$ & $\boldsymbol{\rho}$ \\
\hline Attractiveness & .20 & .01 \\
Hopefulness & & \\
\hline
\end{tabular}

The result as shown in Table 2, there was no significant interaction effect between gender and any level of perceived attractiveness on hopelessness $\left[F_{(1,149)}=0.00, \rho=.991\right]$.

The result similarly indicated no significant interaction effect existed between the strength of faith and perceived attractiveness on students' feelings of hopelessness $\left[F_{(1,149)}=.00, \rho=.991\right]$.

Furthermore, there was no significant interaction effect between school and perceived attractiveness on hopelessness $\left[F_{(1,149)}=1.97, \rho=.163\right]$. The result however showed a significant effect of religiosity on hopelessness $\left[F_{(1,149)}=10.53, \rho=.001\right]$. Thus, that students who were high on religiosity [mean $=63.97$ ] are more hopeful than adolescents low on religiosity $($ mean $=58.78)$.

Table 2. Summary of ANOVA table of gender school type, physical attractiveness and religiosity on hopelessness

\begin{tabular}{|l|l|l|l|l|l|}
\hline Source of Variance & Sum of Squares & $\boldsymbol{d f}$ & $\begin{array}{l}\text { Mean } \\
\text { Square }\end{array}$ & F-Ratio & $\boldsymbol{\rho}$ \\
\hline Gender & 32.61 & 1 & 72.76 & 2.03 & .342 \\
\hline ST & 83.36 & 1 & 83.36 & 2.32 & .130 \\
\hline PA & 12.56 & 1 & 12.56 & .35 & .555 \\
\hline Religiosity & 377.89 & 1 & 377.886 & 10.53 & .001 \\
\hline Gender * ST & .11 & 1 & .110 & .003 & .956 \\
\hline Gender * PA & .01 & 1 & .005 & .000 & .991 \\
\hline Gender * Religiosity & 5.67 & 1 & 5.67 & .158 & .692 \\
\hline ST ${ }^{*}$ PA & 70.65 & 1 & 70.65 & 1.97 & .163 \\
\hline ST Religiosity & 3.57 & 1 & 3.57 & .10 & .753 \\
\hline PA ${ }^{*}$ Religiosity & .004 & 1 & .00 & .00 & .991 \\
\hline Gender * ST * PA & 4.65 & 1 & 4.65 & .13 & .720 \\
\hline Gender * ST * Religiosity & 14.76 & 1 & 14.76 & .41 & .522 \\
\hline Gender * PA * Religiosity & .20 & 1 & .199 & .006 & .941 \\
\hline School * PA * Religiosity & 6.68 & 1 & 6.68 & .19 & .667 \\
\hline Total & 5863.973 & 149 & & & \\
\hline
\end{tabular}

ST: Type of school; PA: Perceived attractiveness

\section{Discussion}

Findings from this study suggest that there is a positive relationship between adolescents' perceived physical attractiveness and hopefulness; which is also consistent with the study done by Page (1992). This suggests that, adolescents who perceive themselves as physically attractive will also perceive having increased opportunities in jobs, dating relationships, among others. This deduction buttresses an old adage that says; what is beautiful is good and that one's success is linked to how beautiful he/she is (Dion, Bersheid, \& Walster, 1972). The systematic review by Anakwah et al. (2015) even suggested that decision making in the court room are likely to favour physically attractive people. Hence, such perceptions have been ingrained in most adolescents thereby influencing their hopefulness.

This study also revealed no interaction effect between gender and perceived attractiveness on hopefulness. This is confirms study by Talbot (2012) who found that men and women's ratings of self-perception of attractiveness did not significantly differ. However, the research conducted by 
Lewis and Rosenblum (1999) does not support this finding. According to Lewis and Rosenblum (1999), sex differences were not significant until age 15 (which falls under the definition for adolescence). The inconsistency in this study's finding with some other previous study could be attributed to the fact that, Lewis and Rosenblum (1999) for example, only studied gender differences in perceptions of attractiveness and did not examine the interaction effect of gender and perception of attractiveness on hopefulness. However, this study investigated perceptions of attractiveness in relation to hopefulness; some past studies did not consider hopefulness as a variable. The reason for the inconsistency in finding could also be due to the differences in culture and socialization in the Ghanaian society and other Western counties. In Ghana, being hopeful or hopeless may not be heavily dependent on one's perceived physical attractiveness like in some Western societies that place much emphasis on modelling, but rather on other variables such as socioeconomic status and social network.

Additionally, the study did not show a significant interaction effect between school and perceived attractiveness on hopelessness. This finding comes to support findings by Masi de Casanova (2004). Results from his study indicated that the lower class (Colegio Amazonas) scored lower on the body and self-esteem questionnaire than those from the middle and upper class (Santa Fé). However, since the Amazonas valued being "arreglada", or making the best out of what they had and also complemented each other, it was observed that it reduced hopelessness among them. Therefore, a plausible reason for this result may be due to the fact that like the Amazonas, students from less-endowed schools do value being "arreglada" and do often complement each other thereby increasing feelings of hopefulness in them. Also, from the demographics, it was observed that a large percentage of students from a well-endowed school had parents who were professionals (doctors, engineers etc.) and were highly educated (tertiary and postgraduate). Therefore, another reason may be that because of the high educational standards and social statuses of their parents, the students generally had a high self-esteem just like the middle and upper class Sante Fé group in Masi de Casanova (2004) thereby increasing hopefulness in them.

The study did not find any significant interaction effect between religiosity and perceived attractiveness on hopefulness. Thus, adolescents who had a higher religious faith and perceived themselves as physically unattractive were not more hopeful than adolescents who had a comparatively lower religious faith and perceive themselves as physically unattractive. This finding is however not consistent with a study by Ellison (1993) which found that frequent participation in

church communities appears to moderate the negative consequences of physical unattractiveness for black self-esteem. However as mentioned earlier on, a possible reason why religiosity and perceived attractiveness had not been seen to have any significant difference on hopefulness may be due to cultural and socialization differences in Ghana and the other Western societies. The inconsistency may however be attributed to the fact that the current study sampled adolescents while Ellison's (1993) study sampled both young and old people in his study. In addition, the current study sampled people from diverse religious backgrounds whilst the study by Ellison sampled only Christians. Adolescents who were high on religiosity were however found to be more hopeful than those who were low on religiosity.

\section{Conclusion}

Results from the study showed a significant relationship between perceived physical attractiveness and hopefulness. According to literature, feelings of hopelessness have a lot of negative implications on an individual. This can however be controlled if practical steps to promote psychosocial empowerment of individuals; especially adolescents are carried out.

\section{Conflict of Interest Statement}

The authors declare that they do not have any conflict of interest.

\section{References}

1. Abrams, K.K., Allen, L.R. \& Gray, J.J. (1993) Disordered eating attributes and behaviours, psychological adjustment and ethnic identity: A comparison of Black and White female college students. International Journal of Eating Disorders, 14(1), 49-57.

2. Anakwah, N., Wiafe-Akenteng, C. B., \& Parimah, F. (2015). "Judging a book by its cover": A legal psychological review of target's physical appearance and legal decisions. European Journal of Psychological Studies, 5(1), 4-8. 
3. Beck, A. T. (1986). Hopelessness as a predictor of eventual suicide: an overview. In J. J. Mann and M. Stanley (Eds.). Psychology of suicidal behaviours. New York: The New York Academy of Sciences.

4. Beck, A. T., \& Steer, R. A. (1988). Manual for the Beck Hopelessness Scale. San Antonio, TX: Psychological Corp.

5. Beck, A. T., Weissman, A., Lester, D, \& Trexler, L. (1974). The measurement of pessimism. The Hopelessness Scale. Journal of Consulting and Clinical Psychology, 42, 861-865.

6. Beck, A.T., Kovacs, M., \& Weissman, A. (1975). Hopelessness and suicidal behaviour: An overview. Journal of the American Medical Association, 234, 1146-1149.

7. Beck, J. S. (1995).Cognitive therapy: Basics and beyond. New York: Guilford Press.

8. Bersheid, E., \& Walster, E. (1972). Beauty and the beast. Psychology Today, 5, 42-46.

9. Bersheid, E., Walster, E., \& Borhstedt, G. (1973).The happy American body: A survey report. Psychology Today, 11, 119-131.

10. Brooks-Gunn, J., \& Peterson, A. C. (1983). Girls at puberty: Biological and psychological perspective. New York: Plenum.

11. Bryne, D., Ervin, C.R., \& Lambert, J. (1970). Continuity between the experimental study of attraction and real life computer dating. Journal of Personality and Social Psychology, 157-165.

12. Cash, T. F., \& Jandra, L. H. (1984). The eye of the beholder. Psychology Today, 12, 46-52.

13. Chambers, J. W., Clark, T., Dantzler, L., \& Baldwin, J. A. (1994). Perceived Attractiveness, Facial Features and American Self-Consciousness. Journal of Black Psychology, $20,305-324$.

14. Cohen, J. (1992). A power primer. Psychological Bulletin, 112, 155-159.

15. Dion, K. K., Bersheid, E., \& Walster, E. (1972). What is beautiful is good. Journal of Personality and Social Psychology, 24, 285-290.

16. Ellis, E. (2008). Child custody evaluations. In R. L. Jackson (Ed.), Learning Forensic Assessment (pp. 417-448). New York: Taylor and Francis.

17. Ellison, C. G. (1993). Religious Involvement and Self-Perception among Black Americans. Social Forces, 71(4), 1027-1055.

18. Eme, R., Maisak, R., \& Goodale, W. (1979). Seriousness of adolescent problems. Adolescence, 14, 93-99.

19. Forintos, P. D., \& Sallai, J. (2010). Adaptation of the Beck Hopelessness Scale in Hungary. Psychological Topics, 2, 307-321.

20. Freedman, R. E. K., Carter, M. M., Sbrocco, T., \& Gray, J. J. (2004). Ethnic differences in preferences for female weight and waist-to-hip ratio: A comparison of African American and White American college and community samples. Eating Behaviours, 5, 191-198.

21. Harris, M. B., Walters, L.C., \& Waschull, S. (2001). Body image and weight as correlates of eating behaviours for African-American college females. Journal for Social and Behavioural Sciences, 38(1), 31-41.

22. Henggeler, S.W., \& Borduin, C. M. (1990). The treatment of difficulties in peer relations. In S.W. Henggeler and C.M. Borduin (Eds.). Family therapy and beyond: A multisystematic approach to treating behaviour problems of children and adolescents. Pacific Grover CA: Brooks Cole Publication Company.

23. Homan, K. J., \& Boyatzis, C. J. (2009). Body Image in Older Adults: Links with Religion and Gender. Journal of Adult Development, 16, 230-238.

24. Kashani, J. H., Reid, J. C., \& Rosenberg, T. K. (1989). Levels of hopelessness in children and adolescents: A development perspective. Journal of Consulting and Clinical Psychology, 57, 496-499.

25. Kleck, R. E., Richardson, S.A., \& Roland, L. (1974). Physical appearance cues and interpersonal attraction in children. Child Development, 45, 305-310.

26. Langlois, J. H., Roggman, L. A., Cassey, R. J., Ritter, J. M., Rieser-Danner, L. A., \& Jenkins, V. Y. (1987). Infant preferences for attractive faces: Rudiments of the stereotype. Developmental Psychology, 23(3), 363-369.

27. Lerner, R. M., \& Foch, T. T. (1987). Biological-psychosocial interactions in early adolescents: A lifespan perspective. Hilldale; NJ: Erlbaum.

28. Lewis, M., \& Rosenblum, G. D. (1999). The Relations among Body Image, Physical Attractiveness and Body Mass in Adolescence. Child Development, 70(1), 50-64. 
29. Masi de Casanova, E. (2004). "No ugly women": Concepts of Race and Beauty among Adolescent Women in Ecuador. Gender and Society, 18(3), 287-308.

30. Padin, M.A, Lerner, R.M., \& Spiro, A. (1981). Stability of body attributes and self-esteem in late adolescence. Adolescence, 161, 371-184.

31. Page, R.M. (1992). Feelings of physical unattractiveness and hopelessness among high school students. The High School Journal, 75(3), 150-155.

32. Perry, N.Y. (1992). Why it's so tough to be a girl. Fortune, 82-84.

33. Plante, T. G., \& Boccaccini, M. T. (1997). The Santa Clara Strength of Religious Faith Questionnaire. Pastoral Psychology, 45, 375-387.

34. Rauste-von Wright, M. (1989). Body image satisfaction in adolescent girls and boys: A longitudinal study. Journal of Youth and Adolescence, 18, 71-83.

35. Swami, V. et al. (2007). Evaluating self and partner attractiveness of oneself and one's romantic partner. Journal of Individual Difference, 3o(1), 35-43.

36. Talbot, T. L. (2012). Comparing self-perception of attractiveness and overall life satisfaction: The differences between men and women. Doctoral dissertation, Western Carolina University.

37. Tucker, C. A. (1983). Self Concept: A function of self-perceived somatotype. Journal of psychology, 113, 123-133.

38. Vaghn, B., \& Langlois, J. H. (1983). Physical attractiveness as a correlate of peer status and social competence in pre-school children. Developmental Psychology, 19, 561-567

39. Wilson, D. B., Sargent, R., \& Dias, J. (1994). Racial difference in selection of ideal body size by adolescent females. Obesity Research, 2(1), 38-48.

УДК 159.9

\title{
'Непривлекательные, настолько безнадежны?' Чувства физической непривлекательности и бесперспективности среди учащихся старших курсов
}

\author{
Глориа Бааба Агрей а, * \\ Нкансах Анаквах a, b, с \\ Джейкоб Овсу Сарфо c, d, e
}

a Университет Ганы, Гана
b Методический университетский колледж, Гана
c KAD International, Гана
d Университет Кэйп Кост, Гана
е Международный университетский колледж, Гана

Аннотация. Данное исследование было призвано изучить влияние чувств непривлекательности на ощущение бесперспективности среди подростков. С помощью кросс-секционного опроса, всего 150 участников старшей школы были отобраны для исследования. Для достижения цели данного исследования - изучить влияние взаимодействия на чувство безнадежности были исследованы следующие факторы: пол и привлекательность, школа и привлекательность, религиозность и привлекательность. Результаты показали, что существует значительная положительная связь между восприятием физической привлекательности и оптимизма. В статье обсуждаются результаты исследования.

Ключевые слова: привлекательность, непривлекательность, безысходность, надежда, пол, религиозность, старшей школы, студент.

\footnotetext{
${ }^{*}$ Корреспондирующий автор

E-mail addresses: babsygrey@gmail.com (Г.Б. Агрей), anaben.afrique@hotmail.com (Н. Анаквах), sarfojo@yahoo.com (Дж.О. Сарфо)
} 